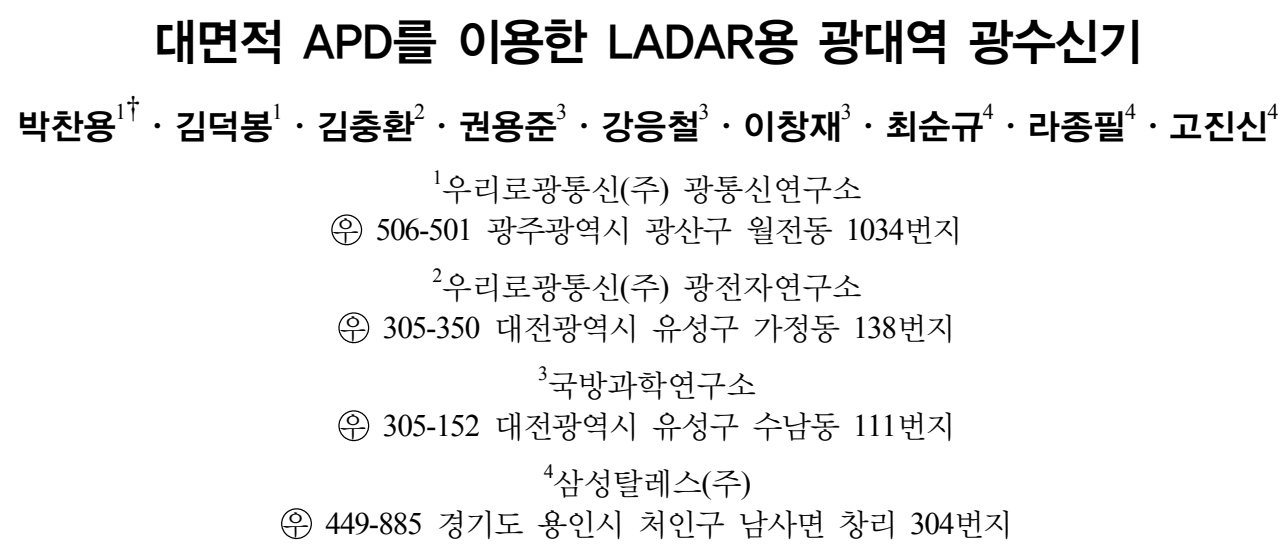

(2012년 11월 26일 받음, 2012년 12월 28일 수정본 받음, 2013년 1월 3일 게재 확정)

본 논문에서는 3차원 영상을 위한 LADAR(LAser Detection And Ranging)용 광검출기 모듈을 설계-제작하고 그 특성을 측정한 결과를 보고한다. 광검출기 모듈은 광파이버 어레이와 접속될 수 있도록 $200 \mathrm{um}$ 직경을 갖는 InGaAs $\mathrm{APD}$ (Avalanche Photodiode) 로 설계-제작하였으며, 선형모드 동작 특성을 만족하도록 TIA(Trans-impedance Amplifier)를 설계-제작하였다. 광검출기 모듈을 구성하는 핵심부품들은 12 개의 lead pin을 갖는 TO8 상에 집적되었으며, 집적에 필요한 APD 서브마운트 및 TIA 회로 등을 자체 적으로 설계-제작하여 사용하였다.

제작한 광검출기 모듈은 $450 \mathrm{ps}$ 의 rising time과 $780 \mathrm{MHz}$ 의 대역폭 특성을 보였으며, $0.8 \mathrm{mV}$ 이하의 잡음 특성과, $150 \mathrm{nW}$ 의 MDS(Minimum Detectable Signal) 신호 크기에 대해 15 이상의 신호대 잡음비(SNR)를 보임으로써 설계한 모든 특성을 만족하였는 데, 이는 저자들이 아는 한 $200 \mathrm{um}$ 직경의 대면적 $\mathrm{InGaAs} \mathrm{APD}$ 를 이용한 광수신기에서 가장 우수한 특성을 나타낸 것이다.

\title{
Wideband Receiver Module for LADAR Using Large Area InGaAs Avalanche Photodiode
}

\author{
Chan-Yong Park ${ }^{1 \dagger}$, Dug-Bong Kim ${ }^{1}$, Chung-Hwan Kim², Yongjoon Kwon ${ }^{3}$, EungCheol Kang ${ }^{3}$, \\ Changjae Lee ${ }^{3}$, Soon-Gyu $\mathrm{Choi}^{4}$, Jongpil La ${ }^{4}$, and Jin Sin Ko ${ }^{4}$ \\ ${ }^{1}$ Optical Communication Research Lab., Wooriro OTC, 1034 Woljeon-dong, Gwangsan-gu, Gwangju 506-501, Korea \\ ${ }^{2}$ Optoelectronics Lab., Wooriro OTC, 138 Gajeong-dong, Yusong-gu, Daejeon 305-350, Korea \\ ${ }^{3}$ Agency for Defense Development, 111 Sunam-dong, Yusong-gu, Daejeon 305-152, Korea \\ ${ }^{4}$ Samsung Thales Co. Ltd., 304 Chang-li, Namsa-myun, Cheoin-gu, Yongin 449-886, Korea
}

(Received November 26, 2012; Revised manuscript December 28, 2012; Accepted January 3, 2013)

In this paper, we report design, fabrication and characterization of the WBRM (Wide Band Receiver Module) for LADAR (LAser Detection And Ranging) application. The WBRM has been designed and fabricated using self-made APD (Avalanche Photodiode) and TIA (Trans-impedance Amplifier). The APD and TIA chips have been integrated on 12-pin TO8 header using self-made ceramic submount and circuit.

The WBRM module showed $450 \mathrm{ps}$ of rise time, and corresponding $780 \mathrm{MHz}$ bandwidth. Furthermore, it showed very low output noise less than $0.8 \mathrm{mV}$, and higher SNR than 15 for $150 \mathrm{nW}$ of MDS(Minimum Detectable Signal). To the author's knowledge, this is the best performance of an optical receiver module for LIDAR fabricated by 200 um InGaAs APD.

Keywords: InGaAs APD, LIDAR, LADAR, Avalanche photodiode, Light detection and ranging OCIS codes: (040.1345) Avalanche photodiodes (APDs); (040.5160) Photodetectors; (250.1345) Avalanche photodiodes (APDs); (280.3400) Laser range finder; (280.3640) Lidar

\footnotetext{
†E-mail: cypark@wooriro.com

Color versions of one or more of the figures in this paper are available online.
} 


\section{I. 서 론}

LIDAR(Light Detection And Ranging) 기술 ${ }^{[1]}$ 은 빛의 TOF (time-of-flight) 방식의 거리 측정기술을 이용한 것으로 3 차 원 영상획득기술로 많이 활용되며, LADAR(Laser Detection And Ranging)로 부르기도 한다. TOF 는 ${ }^{[2]}$ 펄스광원을 조사하 고 반사되는 빛을 광검출기로 검출하여 펄스의 왕복 시간과 세기를 측정함으로써 물체와의 거리를 측정하는 방식으로 광원과 광검출기에 따라 여러 방면에 응용될 수 있다. 광원 을 넓은 영역에 조사하고, 광검출기를 배열화 하여 검출기의 각 셀마다 광펄스의 왕복시간을 측정하는 방식은 3 차원 영 상획득의 한 방법인데 이러한 방식을 Flash LADAR라 부르 며, ASC사(Advanced Scientific Concepts)에서는 flash LADAR 기술을 이용한 3 차원 영상 카메라의 제품화에 성공하였다. ${ }^{[3]}$ 이러한 flash LADAR에 있어서 광검출기 어레이가 핵심 부 품으로 광검출기 배열기술에 많은 연구가 이루어지고 있 다. ${ }^{[4]-[6]} 3$ 차원 영상을 얻는 또 다른 방법으로 레이저를 배열 화 하거나 회전거울 등을 이용하여 광원을 2 차원으로 주사 하는 방식이 있다. 이러한 방식을 Scanner LADAR라 부르며 Velodyne사에서는 64 개의 광원 어레이를 이용하여 3 차원 영 상획득에 성공하였다. ${ }^{[7]}$

광검출기에는 주로 $\mathrm{APD}$ (Avalanche Photodiode)가 활용되 고 있는데, 이는 보다 먼 거리의 3 차원 영상을 획득하기 위 한 것이다. $\mathrm{APD}$ 에는 Linear mode에서 동작하는 $\mathrm{APD}$ 와 Geiger-mode(GM)에서 동작시키는 $\mathrm{APD}$ 의 두 종류가 활용되 고 있다. $\mathrm{GM}-\mathrm{APD}$ 는 항복 전압 이상에서 구동하여 신호의 크기를 10,000 배 이상 증폭시키므로 전치증폭기가 필요 없 는 대신 입력광의 세기와 무관하게 출력 광전류가 일정하므 로 $\mathrm{APD}$ 의 디지털 모드라고도 불린다. $\mathrm{APD}$ 를 항복전압 이 하의 영역에서 동작시킬 경우 증폭이 10 100 정도에서 사 용하게 되며, 전치증폭기가 필요하게 된다. 이 때 출력신호 의 크기는 입력광신호의 세기에 따라 비례하므로 선형모드 라고 부르게 된다. 가이거 모드는 되 돌아오는 시간(거리)만 측정하므로 반사율에 따른 재질의 구분이 힘드나, 선형모드 는 되돌아 오는 시간(거리)뿐만 아니라 반사광의 세기를 구 분할 수 있으므로 영상 구현이 보다 쉽게 이루어질 수 있는 장점이 있다. 또한, 가이거모드 $\mathrm{APD}$ 는 증폭이 매우 크기 때 문에 매우 약한 광신호의 수신이 가능하여 먼 거리의 영상 구현을 가능하게 하나, 개별 칩의 동작 속도가 느리므로 빠 른 동작속도를 요구하는 스캐너 타입에서는 사용하기 어려 운 단점을 가지고 있다. 사용 재료 측면에서 보면 Eye-safety 가 강조됨에 따라 로봇이나 자동차 등에 응용되는 레이저 파 장이 $1550 \mathrm{~nm}$ 대로 천이하고 있고, 따라서 이 파장대역에서 수신감도가 가장 좋은 InGaAs-APD가 매우 중요하게 부각되 고 있다.

본 연구에서는 7개의 광섬유 어레이로 구성되는 Scanner 타입의 광원에 대해 동작하는 단일 선형모드 $\mathrm{InGaAs-APD}$ 광검출기를 성공적으로 제작한 결과에 대해 보고한다.

\section{II. 광검출기의 구성 요건 및 설계}

광검출기로 입사하는 광신호의 구성은 그림 1 과 같다. 광 섬유레이저 신호가 1번-7번으로 구성되어 있으며 수광부에 서도 1번-7번으로 구성된 광섬유어레이로 광신호를 수신한 다(그림 1 의 a). 광섬유는 (그림 1 의 b)와 같이 번들 형태로 구성되어 광검출기로 입사하게 된다. 광섬유어레이와 광검출 기 사이에 렌즈가 있어 광신호를 집광하여 광검출기 표면으 로 입사하게 된다.

광원에서 광펄스가 1 번부터 순차적으로 발사하게 되는데 이 때 광펄스와 광펄스 사이는 $330 \mathrm{~ns}$ 의 간격을 가지고 있으 며, 광원의 펄스모양은 $1 \mathrm{~ns}$ 의 펄스 반치폭을 갖는 가우시안 모드로 근사하였다. 또, 광섬유 코아의 직경은 $160 \mathrm{um}$, 클래 딩의 직경이 $180 \mathrm{um}$ 이므로 광섬유 7 가닥의 직경(그림1의 b)은 최소 $540 \mathrm{um}$ 이상이며, 광파가 코아에 모여 있다고 할 때 광파의 직경은 최소 $500 \mathrm{um}$ 이상이다. 따라서 렌즈의 성 능을 고려하여 광검출기의 수광면적은 최소 $200 \mathrm{um}$ 이상의 요건이 있다.

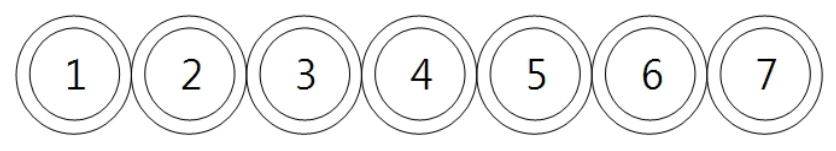

(a)

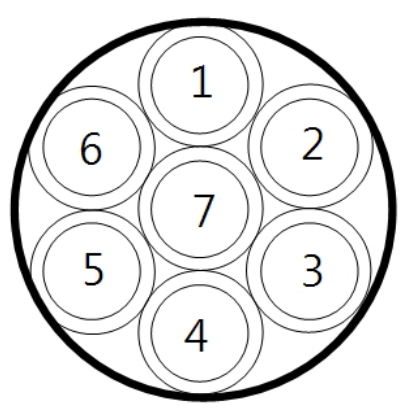

(b)

FIG. 1. Light-receiving technique from the array optical signal by using single APD: (a) Crossectional View of fiber array in the receiving side, (b) Crossectional View of input fiber array to detector.

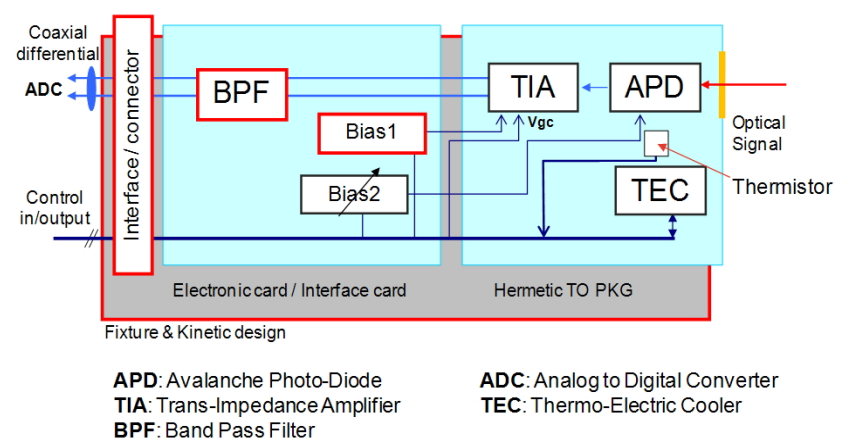

FIG. 2. Functional block diagram of optical receiver module. 
광검출기는 수광 직경 $200 \mathrm{um}$ 이상을 갖는 $\mathrm{APD}$ 칩과 광 전류를 증폭하는 증폭기 회로(TIA: Trans-impedance Amplifier) 가 핵심 부품이고, 그 외 바이어스 공급회로, APD 보호회로, 잡음차단 필터, TEC 및 thermistor로 구성되며, 그림 2에 광 검출기의 구성 및 기능 블록도를 나타내었다. TIA의 설계를 위해 APD 칩의 parameter를 분석하고 이로부터 TIA를 설계 하였다. TIA 설계 및 제작에 관해서는 참고문헌 8 에 상세히 기술되어 있다.

$\mathrm{APD}$ 의 Capacitance $\left(\mathrm{C}_{\mathrm{APD}}\right)$ 는 $\mathrm{TIA}$ 의 잡음을 크게 증가시키 고, $\mathrm{RC}$ 시정수에 의한 대역폭의 제한 요인이므로 가능하면 작게 설계하여야 함은 잘 알려져 있다. $\mathrm{C}_{\mathrm{APD}}$ 를 $2.0 \mathrm{pF}$ 이내 로 제한하기 위한 방법으로 흡수층의 두께를 가능하면 두껍 게 하고(이는 두 charge plate 사이의 거리를 멀게 하는 것에 해당), $\mathrm{APD}$ 칩과 세라믹 기판상에 각각 거울 이미지의 패턴 을 형성하여 flip-chip bonding 형태로 부착하는 구조가 가장 적합할 것으로 예측되는데 이는 bonding pad에 의한 parasitic capacitance를 제거하기 위한 것이다. 이에 따라 설계한 $\mathrm{APD}$ 의 구조도는 그림 3 에 나타낸 것과 같다. 여기서 광 흡수층 의 두께는 $1.8 \mathrm{um}$, 증폭층의 폭은 edge breakdown을 막기 위 해 0.6 um로 하였다. FGR(Floating Guard Ring) 구조에 있어 서 흡수층 두께와 증폭층 너비 $\left(\mathrm{w}_{\mathrm{m}}\right)$ 와의 상관관계는 참고문 헌 9 - 참고문헌 11 에 상세히 기술되어 있다. 전기장 조절층 의 농도는 $1 \times 10^{17} \mathrm{~cm}^{-3}$, 두께는 $0.25 \mathrm{um}$ 로 charge density는 $2.5 \times 10^{12} \mathrm{~cm}^{-2}$ 이다. Grading층은 $\mathrm{InP}$ 와 $\mathrm{InGaAs}$ 의 중간 밴드 갭을 갖는 3 층의 $\mathrm{InGaAsP}$ 로 구성하였으며, 두께는 $0.12 \mathrm{um}$ 로 설계하였다. 증폭이 가장 크게 일어나는 활성영역의 직경 은 $200 \mathrm{um}$ 이고 가드링을 포함한 소자의 직경은 $233 \mathrm{um}$ 이 다. 따라서 예상되는 $\mathrm{C}_{\mathrm{APD}}$ 는 약 $1.7 \mathrm{pF}$ 에 해당한다. 또, 빛이 뒷면입사를 통해 광흡수층을 round-trip 하므로 실제 광경로 상의 $\mathrm{InGaAs}$ 흡수층의 두께는 $3.6 \mathrm{um}$ 에 해당하므로 $\mathrm{M}=1$ 에 서 responsivity는 $1550 \mathrm{~nm}$ 파장에 대해 $1.1 \mathrm{~A} / \mathrm{W}$ 이상에 이를 것으로 예상된다.

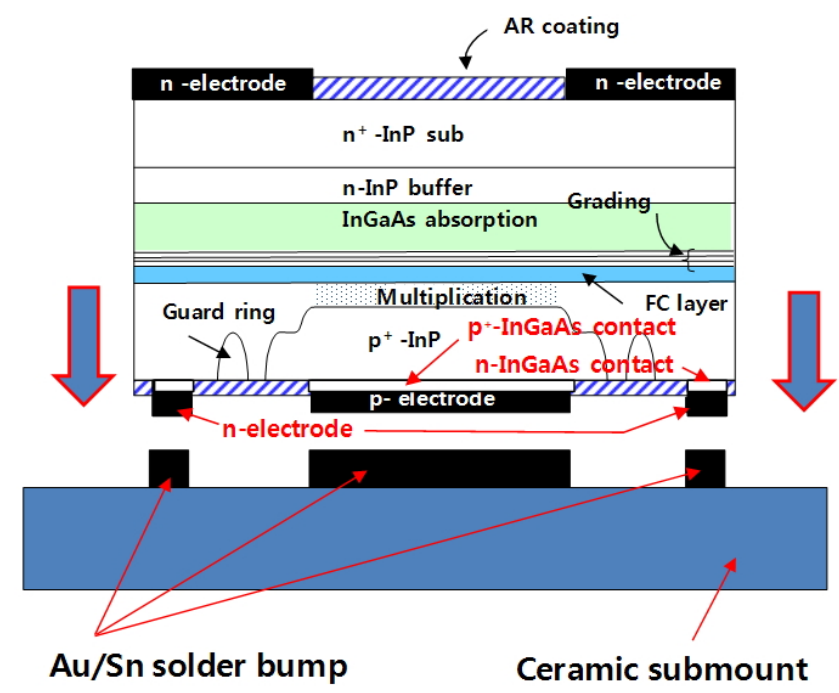

FIG. 3. Cross-sectional view of APD chip on submount.
이러한 APD 칩의 데이터는 TIA 설계 및 광검출기 모듈의 설계에 반영된다. 광검출기의 잡음전력은 $\mathrm{APD}$ 의 잡음 및 TIA의 잡음의 합으로 표시된다. ${ }^{[12]}$ 즉,

$$
\begin{aligned}
& \left\langle i_{a}^{2}\right\rangle_{A P D-R x} \cong\left\langle i_{a}^{2}\right\rangle_{A P D}+\left\langle i_{a}^{2}\right\rangle_{T I A} \\
& \approx 2 q\left(I_{p h}+I_{D M}\right) M^{2} F(M) B+ \\
& \frac{4 k T \Gamma}{g_{m}}\left[\frac{1}{R_{L}^{2}} B+\left(2 \pi C_{T}\right)^{2} B^{3}\right]
\end{aligned}
$$

Where

$$
F(M)=M\left\{1-\frac{(1-k)(M-1)^{2}}{M^{2}}\right\}
$$

여기서, $\mathrm{I}_{\mathrm{ph}}$ 는 광전류, $\mathrm{I}_{\mathrm{DM}}$ 은 증폭되는 암전류, $\mathrm{M}$ 은 $\mathrm{APD}$ 의 증폭률, $\mathrm{F}(\mathrm{M})$ 은 잉여잡음지수(Excess noise factor), $\mathrm{R}_{\mathrm{L}}$ 은 feedback 저항, $\mathrm{C}_{\mathrm{T}}$ 은 $\mathrm{APD}$ 와 TIA gate의 정전용량의 총합, $\mathrm{B}$ 는 대역폭을 나타낸다. $\mathrm{F}(\mathrm{M})$ noise의 경우 증폭이 random 하게 발생하는 것에 기인하는데 Avalanche 증폭에 있어서 전자에 의한 증폭과 정공에 의한 증폭률의 비인 $\mathrm{k}$-값의 함수 이다. 즉 $\mathrm{k}=\alpha / \beta$ 이고, $\alpha$ 는 전자에 의한 단위거리당 증폭횟 수, $\beta$ 는 정공에 의한 단위거리당 증폭횟수를 나타낸다. InP 에서 정공에 의한 증폭이 발생하는 구조이고, $\mathrm{k}=0.3 \sim 0.4$ 의 값을 갖는다.

$\mathrm{APD}$ 의 특성으로부터 Responsivity $=1 \mathrm{~A} / \mathrm{W}, \mathrm{M} \sim 10$ 근처 에서 사용하는 것으로 예상을 하고 출발한다. 먼저 출력 노 이즈 전압이 $1 \mathrm{mV}$ 이하이어야 하므로 $\mathrm{SNR} \geq 10$ 으로부터 신 호의 출력전압이 $10 \mathrm{mV}$ 이상이어야 한다. 따라서 $150 \mathrm{nW}$ 의 $\mathrm{MDS}$ 광신호에 대해 $\mathrm{APD}$ 의 Responsivity 값과 증폭을 고려 하면 신호전류는 $150 \mathrm{nW} \times 1.0 \mathrm{~A} / \mathrm{W} \times 10$ (증폭률)=1.5 uA가 된 다. 이 값을 $10 \mathrm{mV}$ 이상으로 출력시키기 위해서 피드백 저 항은 $7 \mathrm{k} \Omega$ 이상의 요건을 만족해야 한다. $\mathrm{RC}$ 시정수에 의 한 Bandwidth를 고려하여 피드백 저항=7.5 $\mathrm{k} \Omega$ 으로 정하였 다. 또 worst case를 고려하여 $\mathrm{C}_{\mathrm{APD}}=2.0 \mathrm{pF}$ 일 때, TIA에 의 한 잡음전류는 설계치(Ideal)가 $73 \mathrm{nA}$, 온도 및 non-ideality 를 고려한 최대잡음은 $145 \mathrm{nA}$ (worst case), 평균 $115 \mathrm{nA}$ 를 갖도록 설계하였다. ${ }^{[8]}$ 식 (1)의 $\mathrm{APD}$ 에 의한 잡음은 광전류, 암전류 및 증폭에 의한 Shot noise에 해당하며, Excess noise factor, $\mathrm{F}(\mathrm{M})$, 가 곱해진 값으로 주어진다. 따라서 $\mathrm{k}=0.35$ 로 근사하면 $\mathrm{APD}$ 에 의한 noise current는 $\mathrm{APD}$ 의 증폭에 따라 표 1 와 같이 계산된다.

피드백 저항 $7.5 \mathrm{k} \Omega$ 과 $\mathrm{M}=10$ 일 때 표 1 의 값으로부터 Noise voltage는 보통 $0.827 \mathrm{mV}$ 이고 최악의 경우 $1.033 \mathrm{mV}$ 가 된다. 증폭 $\mathrm{M}$ 을 증가시키면 Signal은 증가하게 되고, 잡 
TABLE 1. Noise current as a multiplication factor, $M$

\begin{tabular}{c|c|c|c}
\hline \hline APD 증폭, $\mathrm{M}$ & APD 잡음전류 $(\mathrm{nA})$ & TIA 잡음전류 $(\mathrm{nA})$ Typ./Worst case. & 총 잡음전류 (nA) Typ./Worst case. \\
\hline 10 & 27.5 & $115 / 145$ & $118.2 / 147.6$ \\
\hline 11 & 31.4 & $115 / 145$ & $119.2 / 148.4$ \\
\hline 12 & 35.4 & $115 / 145$ & $120.3 / 149.3$ \\
\hline 13 & 39.6 & $115 / 145$ & $121.6 / 150.3$ \\
\hline 14 & 43.9 & $115 / 145$ & $123.1 / 151.5$ \\
\hline 15 & 48.4 & $115 / 145$ & $124.8 / 152.9$ \\
\hline
\end{tabular}

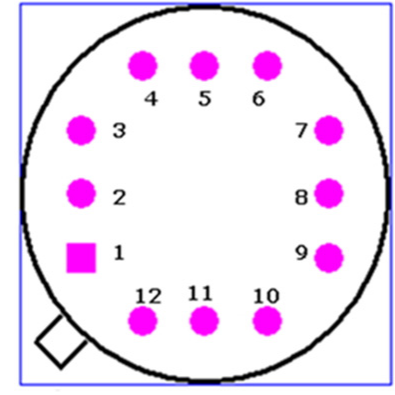

BOTTOM VIEW

\begin{tabular}{|c|l|}
\hline Pin & \multicolumn{1}{|c|}{ Description } \\
\hline 1 & APD bias \\
\hline 2 & Vcc1(1.2V) \\
\hline 3 & Vcc2(3V) \\
\hline 4 & Vgc $(0 \sim 1.2 \mathrm{~V})$ \\
\hline 5 & Voffset \\
\hline 6 & GND \\
\hline 7 & Sig. + \\
\hline 8 & Sig.- \\
\hline 9 & TEC+ \\
\hline 10 & TEC- \\
\hline 11 & Thermistor+ \\
\hline 12 & Thermistor- \\
\hline
\end{tabular}

(a)

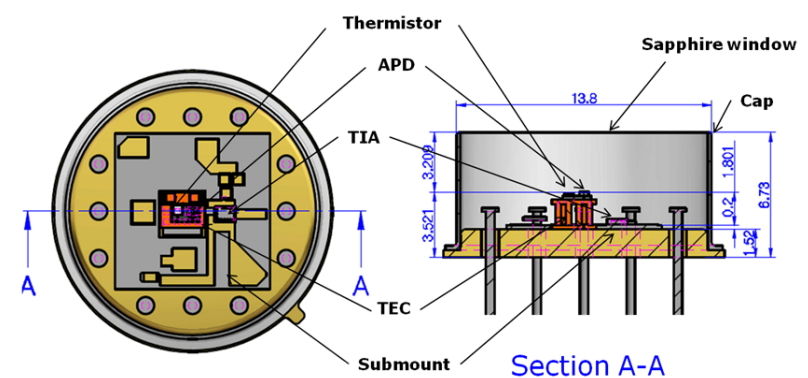

(b)

FIG. 4. Structure of TO module: (a) Bottom view and pin map of TO-module, (b) Top and cross-sectional view of TO module.

음도 증가하게 된다. $\mathrm{APD}$ 의 responsivity가 $1.0 \mathrm{~A} / \mathrm{W}$ 이상(설 계치가 $1.1 \mathrm{~A} / \mathrm{W}$ 이상)이고, Capacitance가 $2.0 \mathrm{pF}$ 이하(설계 치는 $1.7 \mathrm{pF}$ )이므로 최악의 경우라 하더라도 $1 \mathrm{mV}$ 이내의 잡음전압 및 10 이상의 $\mathrm{SNR}$ 을 충분히 얻을 수 있음을 알 수 있다.

광검출기 모듈은 $\mathrm{APD}$ 칩, TIA칩, $\mathrm{TEC}$, Thermistor 등으로 구성되는 핵심 $\mathrm{TO}$ 모듈과 이를 구동하는 회로 3 종으로 구성 된다. APD bias, Vcc 두 종, TIA gain control bias, TEC 바이 어스(독립 GND), Thermistor, 아나로그 신호 출력 두 종 (Data, Data bar) 등 총 12종의 lead pin이 필요하다. 이를 위 해 TO-8 package를 사용하였으며 그림 4에 TO-8 package의 bottom view를 나타내었다.

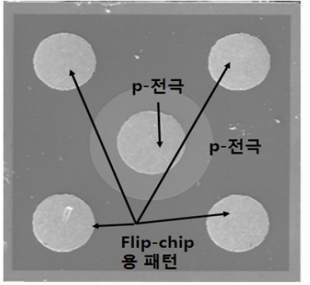

(a)

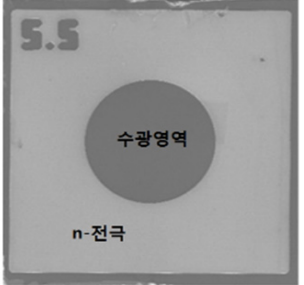

(b)

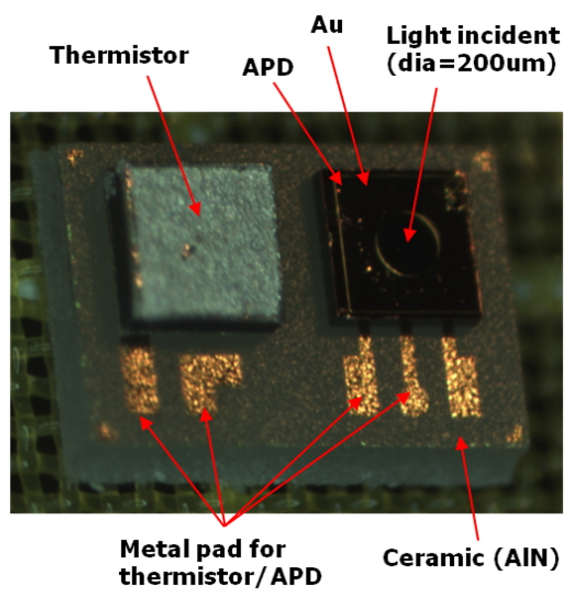

(c)

FIG. 5. Photograph of fabricated APD chip and APD chip-onsubmount: (a) SEM-photograph of APD chip(front-side), (b) SEMphotograph of APD chip(backside), (c) APD chip-on-submount.

\section{III. 제 작}

$\mathrm{APD}$ 칩은 $\mathrm{Zn}$-확산 방법으로 제작하였다. S-doped( $\left.\mathrm{n}^{+}\right) \mathrm{InP}$ 기판 상에 버퍼층, 광흡수층, 그레이딩층, 전기장 조절층, 증 폭층과 $\mathrm{p}$-확산층을 구성하는 window층, Contact-InGaAs층 및 $\mathrm{InP}$ cap층이 차례로 성장된 웨이퍼 상에 활성영역을 식각 으로 에칭하고 $\mathrm{Zn}$-확산을 실시하였다. $\mathrm{Zn}$-확산은 $\mathrm{MOCVD}$ chamber에 DEZn를 흘리면서 수행하는 open tube 방식을 활 용하였다. 이 때, $\mathrm{DEZn}$ 의 유량, 농도 및 확산온도, 기판의 물 질 및 표면상태 등이 매우 중요하며 기판의 도핑농도도 매우 중요한 파라미터가 된다. 확산된 wafer 상에 cap-InP를 제거 하고 $\mathrm{p}$-전극 및 $\mathrm{n}$-전극 하에 있는 옴-접촉층인 $\mathrm{p}^{+}-\mathrm{InGaAs}$ 및 $\mathrm{n}-\mathrm{InGaAs}$ 를 남기고 나머지 $\mathrm{InGaAs}$ 층을 제거한다. 이 때 식 각 마스크로 전극금속 패턴을 활용하였다. 전극 금속패턴이 
제작된 웨이퍼에 $\mathrm{SiNx}$ 표면보호막을 형성하고 contact 부분 의 $\mathrm{SiNx}$ 를 제거한다. 그 위에 $\mathrm{p}$-전극/n-전극을 동시에 형성 하면 APD의 전면 공정이 완성된다. Backside lapping/polishing 후 $\mathrm{SiNx} \mathrm{AR}$ coating공정, 패터닝 공정, Lift-off에 의한 전극 형성 공정을 수행한다. APD 칩은 $500 \mathrm{um} \times 500 \mathrm{um}$, 칩의 두 께는 $200 \mathrm{um}$ 이다. 제작된 $\mathrm{APD}$ 칩은 자체 설계 제작한 $\mathrm{AlN}$

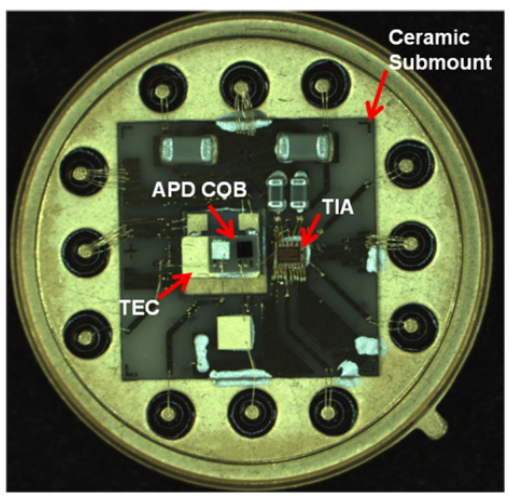

FIG. 6. TO-type optical detector/receiver module.

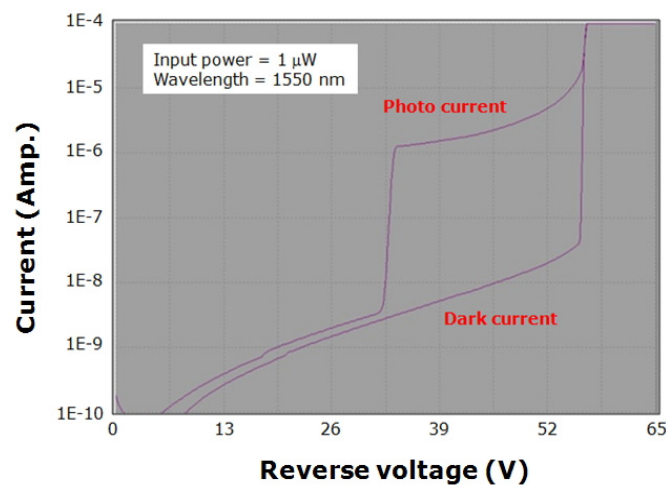

FIG. 7. Dark and photocurrent characteristics.
기판상에 flip-chip bonding으로 부착하였다. 제작이 완료된 칩의 사진을 그림 5 에 나타내었다.

광검출기 $\mathrm{TO}$ 모듈 제작과정은 다음과 같다. 먼저 $\mathrm{APD}$ 칩 과 Thermistor가 부착된 Chip-on-submount(COS)를 TEC 상 단에 부착한다. 다음 방열이 잘 되도록 $\mathrm{TEC}$ 를 $\mathrm{TO}$-header 상 에 직접 부착하되 $\mathrm{APD}$ 칩이 중앙에 오도록 $\mathrm{TEC}$ 의 위치를 조절한다. 각종 회로가 제작된 세라믹 기판 회로(그림 4)에 서 TEC 크기에 해당 부분은 고출력 레이저-cutting 방법으로 제거하였다. 세라믹 기판 상에는 TIA, 저항, 인덕터 및 캐패 시터와 같은 각종 수동부품을 부착할 수 있는 패턴 회로가 제작되어 있다. 각 부품들이 부착되면 Window cap(Sapphire) 을 저항용접 방법으로 부착하였다.

\section{IV. 특성 및 논의}

그림 7에 제작된 APD 칩의 전류-전압 특성을 광신호를 입 사했을 때(Photocurrent)와 광신호가 없을 때(dark current)로 나타내었다. 또, 그림 8 에는 $\mathrm{C}-\mathrm{V}$ 값을 나타내었다. 제작된 $\mathrm{APD}$ 는 $56-62 \mathrm{~V}$ 분포의 항복전압을 나타내었으며, 그림 7로

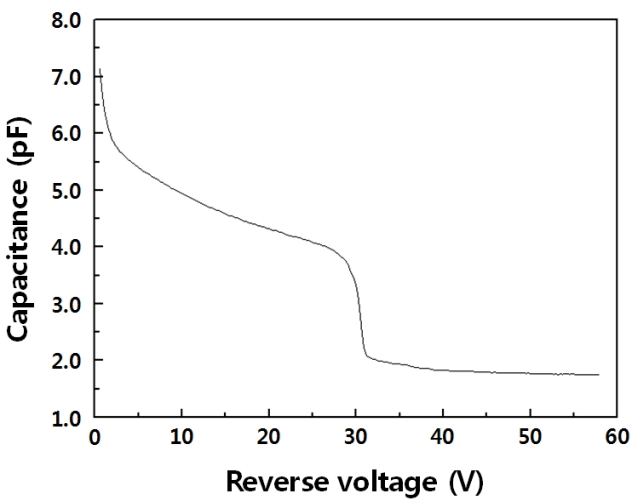

FIG. 8. Capacitance-voltage characteristics.

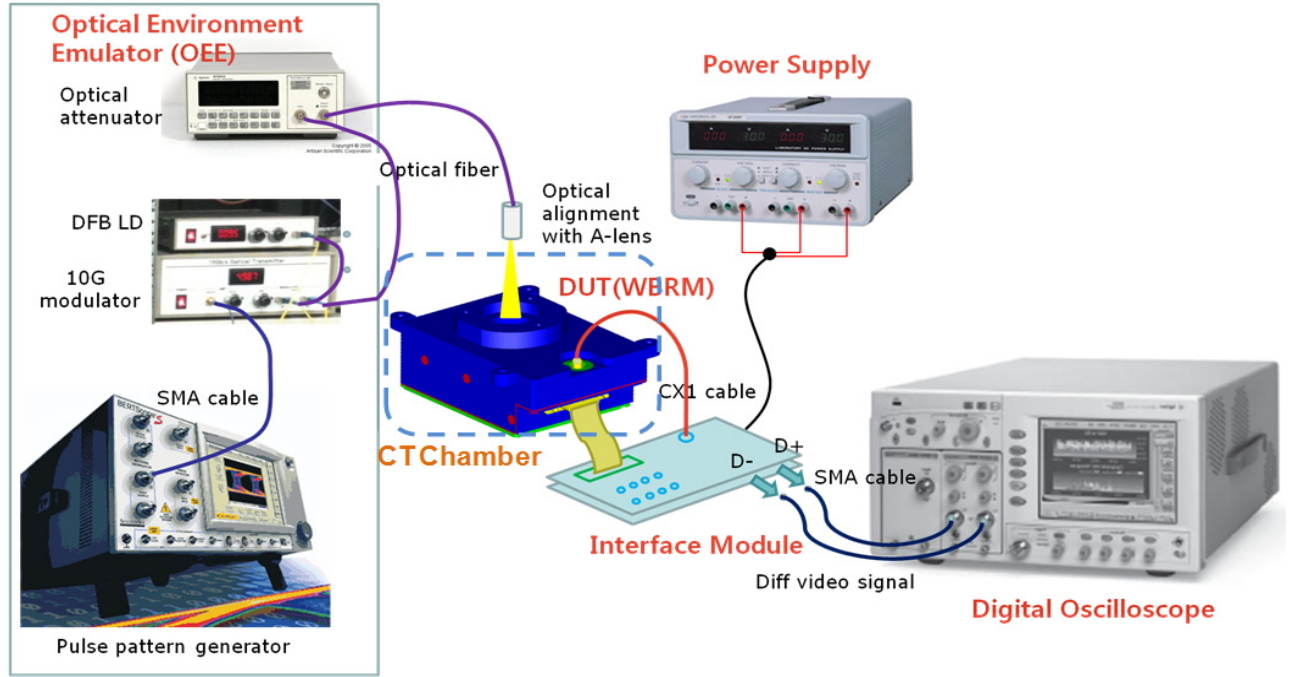

FIG. 9. Measurement system set-up. 
부터 이 $\mathrm{APD}$ 의 항복전압은 $56 \mathrm{~V}$ 근처이고, $32-33 \mathrm{~V}$ 사이에 서 광전류의 급격한 상승이 있으며, 이로부터 $\mathrm{InGaAs}$ 흡수 층의 punch-through 전압이 $32 \mathrm{~V}$ 근처임을 알 수 있다. 항복 전압의 $90 \%$ 에 해당하는 인가전압에서 정의되는 암전류는 1 0 20 nA를 보였다. 0.9 VB에서 Capacitance는 $1.8 \mathrm{pF}$ 이하 를 보임으로써 설계치와 거의 일치하였다. 이 두 파라미터로 부터 APD 칩은 설계대로 제작되었음을 알 수 있다.

제작된 $\mathrm{APD}$ 모듈의 펄스 입력광에 대한 특성을 조사하기 위해 광섬유의 한쪽 끝은 계측기와 연결하기 위한 커넥터로, 다른 끝은 Aspherical lens를 장착하여 APD 표면으로 광의 입사가 가능하도록 광섬유 케이블을 제작하여 사용하였다. 3 차원 정렬이 가능한 $\mathrm{x}-\mathrm{y}-\mathrm{z}$ 스테이지를 이용하여 광섬유와 $\mathrm{APD}$ 를 정렬한 후 각종 케이블과 이 시스템 전체를 체임버 내에 넣고 온도에 따른 특성도 아울러 조사하였다. (그림 9) 에 테스트를 위한 셋업을 나타내었다.

먼저 제작된 모듈의 noise 특성, 펄스 응답 특성을 조사하

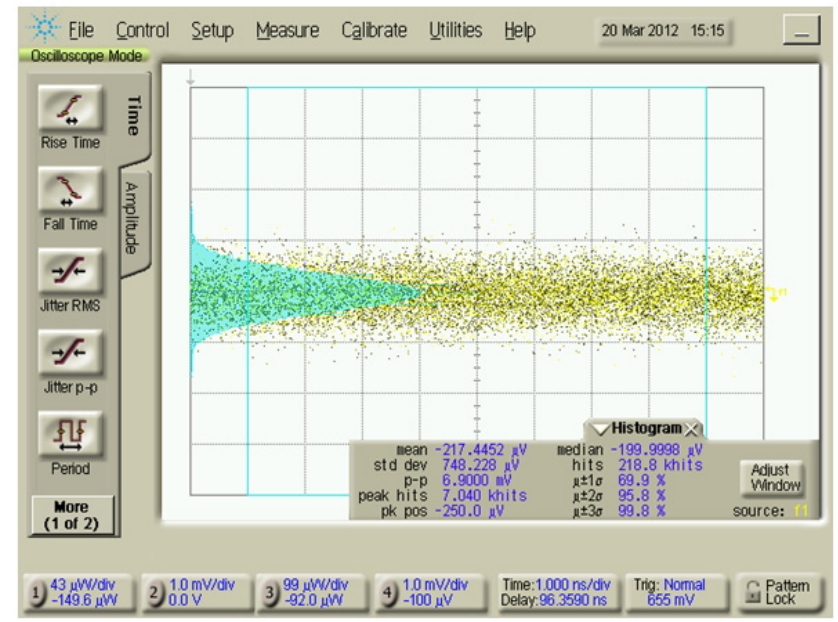

(a)

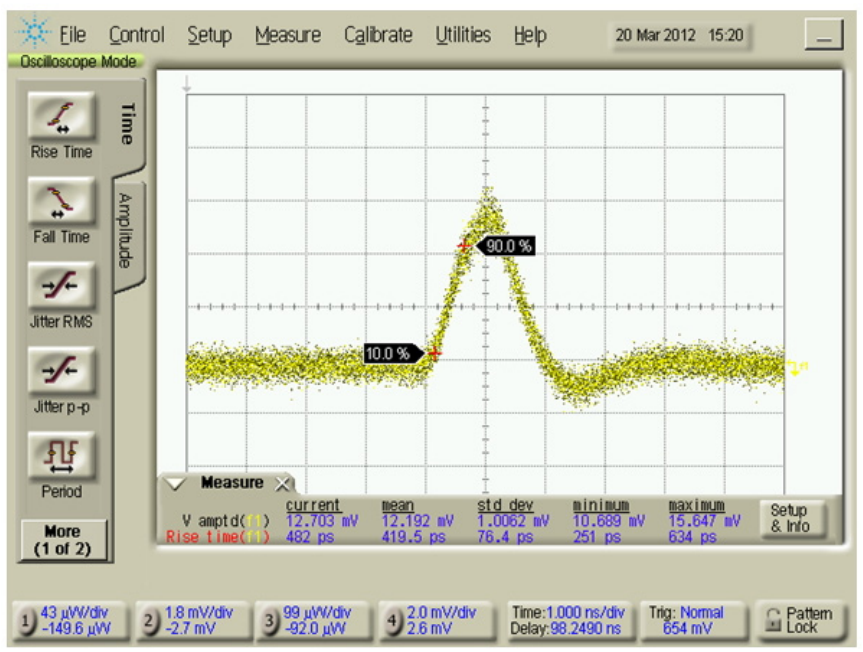

(c)
였으며 (그림 10)에 나타내었다. (그림 10)의 (a)는 모듈의 잡 음 특성을 나타내는데 잡음 특성의 측정은 $\mathrm{APD}$ 에 동작 바 이어스 전압을 가한 상태에서 TIA 에 High-gain mode의 바 이어스 전압을 인가하고 출력을 오실로스코프로 측정하였다. Gaussian 분포의 noise를 관찰할 수 있으며, 제작된 대부분의 모듈은 700-800 uV의 잡음 특성을 보였으며, (그림 10)의 (a) 에 나타낸 데이터는 표준편차로 표현되는 잡음이 $748 \mathrm{uV}$ 임 을 알 수 있으며, 설계치인 $1 \mathrm{mV}$ 보다 낮음을 알 수 있다.

(그림 10)의 (b)는 입력광의 패턴을 나타낸 것이다. 입력광 은 $\mathrm{VOA}($ Variable Optical Attenuator)를 통해 광파워를 조절 한 후 광수신 모듈로 입사된다. (c)는 $1 \mathrm{MDS}$ 크기의 신호 $(150 \mathrm{nW})$ 에 대한 응답 펄스 패턴을 나타내었는데 이 때 TIA 는 high-gain mode로 동작하게 된다. Rising time은 $420 \mathrm{ps,}$ 출력 피크치의 평균은 $12.2 \mathrm{mV}$ 로 $\mathrm{SNR}$ (신호대 잡음비)는 16 정도임을 알 수 있으며, $\mathrm{APD}$ 와 TIA의 설계 및 제작이 매우 우수하게 되었음을 의미한다. (d)는 $500 \mathrm{MDS}$ 크기(75 uW)

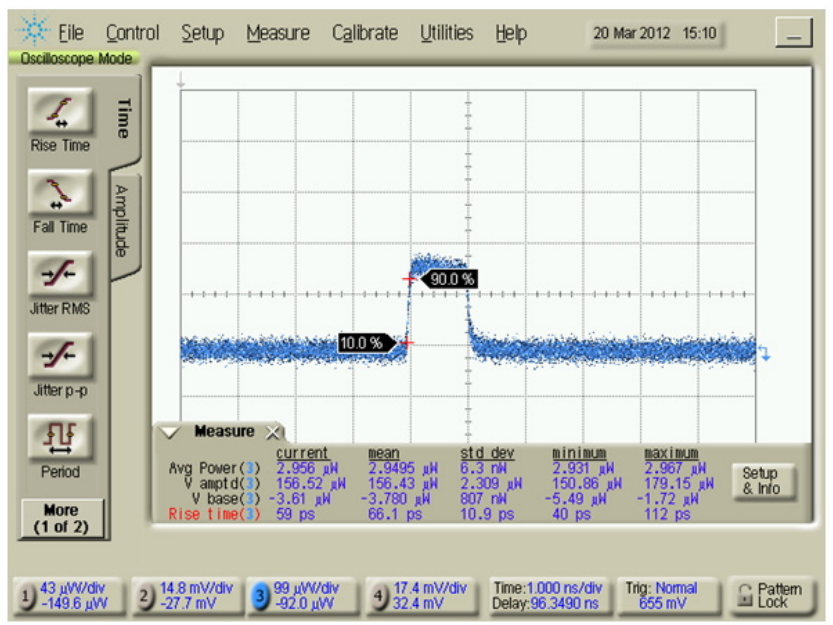

(b)

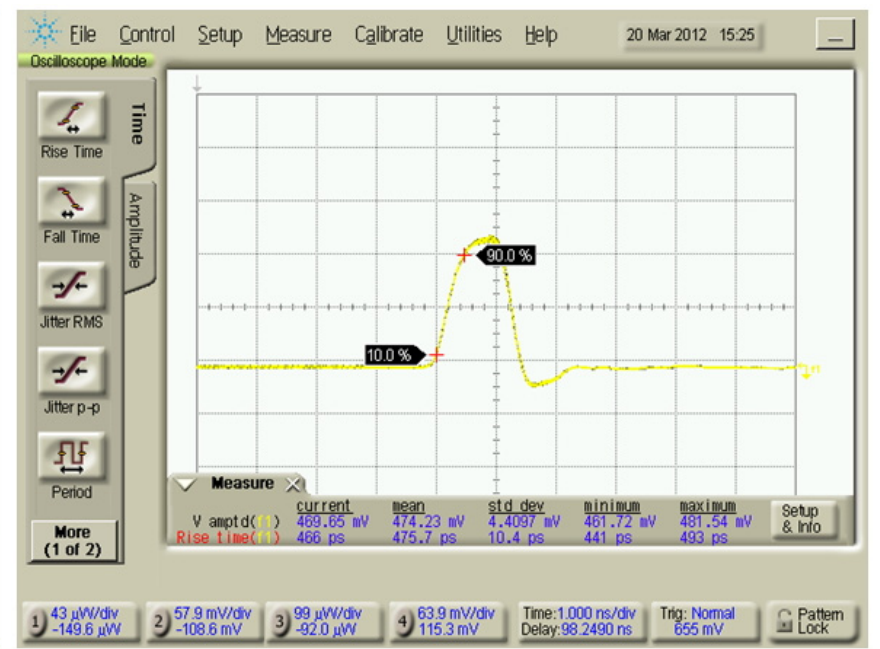

(d)

FIG. 10. Pulse response of the fabricated receiver module for various input signal: (a) No input signal (output noise measurement), (b) Pulse-shape of light source, (c) Pulse response for 1MDS (150 nW, 1 us FWHM) (d) Pulse response for 500 MDS (75 uW, 1 us FWHM). 
의 신호에 대한 응답 패턴으로 TIA는 Low-gain mode로 동 작한다. Rise time은 $476 \mathrm{ps}$, 펄스의 피크는 $474 \mathrm{mV}$ 를 나타 내고 있다. Rising time $\left(t_{r}\right)$ 을 $450 \mathrm{ps}$ 라 보면 펄스 응답의 rising

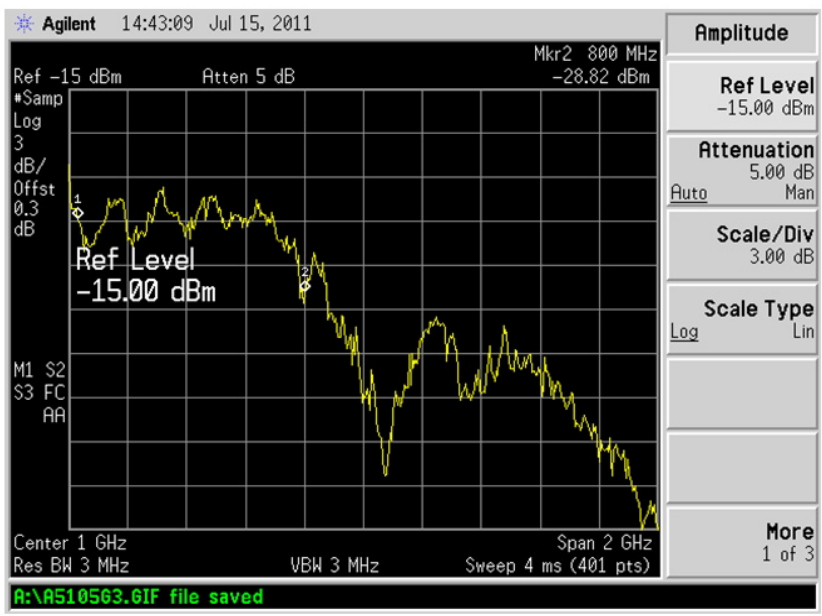

FIG. 11. $-3 \mathrm{~dB}$ bandwidth measurement.

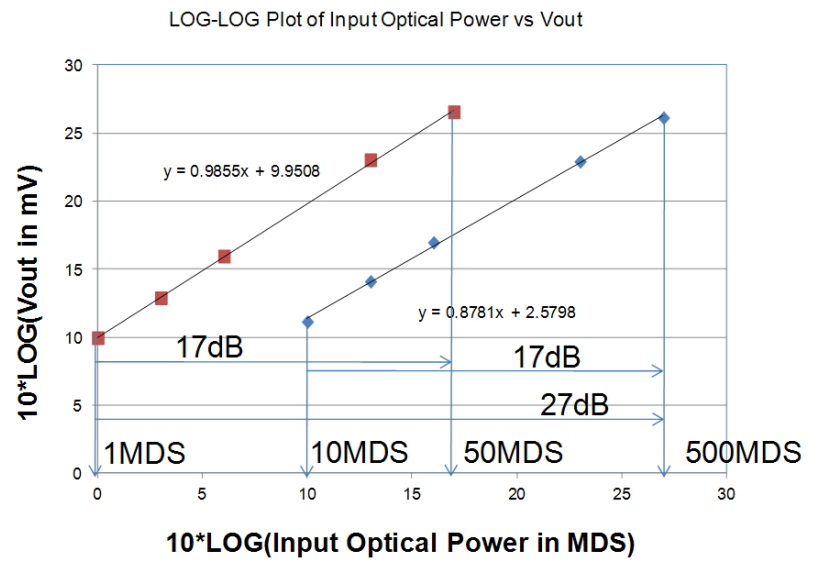

FIG. 12. Dynamic range measurement.

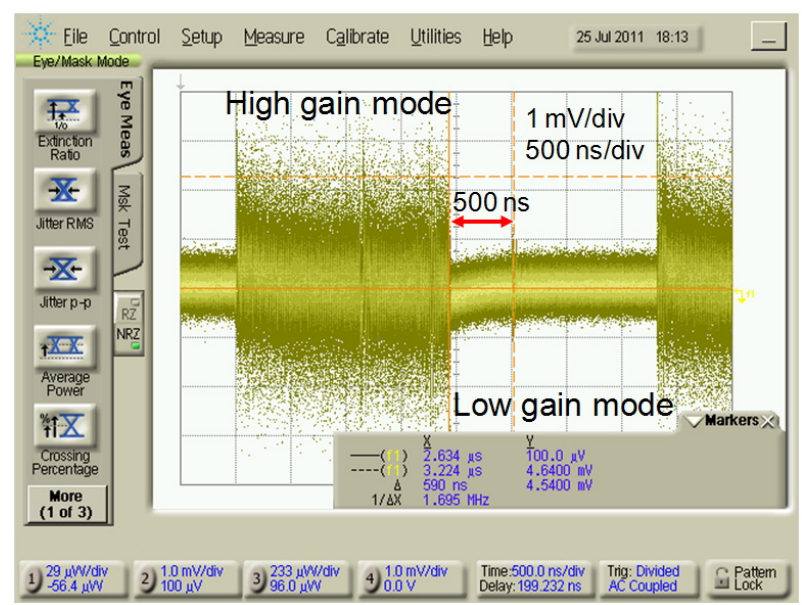

FIG. 13. Measured results of mode switching/stabilizing time. $500 \mathrm{~ns}$ is required for stabilization from high-gain mode to low-gain mode. time과 대역폭과의 상관관계로부터 대역폭이 $780 \mathrm{MHz}$ 임을 알 수 있다. 즉,

$$
B W=\frac{0.35}{t_{r}}=\frac{0.35}{450 \mathrm{ps}} \cong 780 \mathrm{MHz}
$$

(그림 11)은 대역폭을 측정한 것으로 $780 \mathrm{MHz}$ 의 대역폭을 갖는 것을 확인할 수 있다. 대역폭이 넓으면 입력 잡음이 증 가하므로 좋지 않고, 좁게 설계-제작되면 수신감도(MDS)가 나쁘게 된다. 본 연구에서는 $\mathrm{APD}$ 의 정전용량을 $2.0 \mathrm{pF} \sim 2.2$ $\mathrm{pF}$ (최악의 경우)으로 두고 설계하였기 때문에 $\mathrm{APD}$ 의 정전 용량이 $1.7 \mathrm{pF}$ 이하로 줄어 들게 됨에 따라 대역폭이 넓어진 것으로 보이며, 입력잡음 또한 줄어든 것으로 분석되었다. 상용화된 $200 \mathrm{um} \mathrm{APD}$ 의 경우 대부분 $2.2 \sim 2.4 \mathrm{pF}$ 을 보이고 있다.

본 연구에서 제작한 고속 광대역 광수신모듈(WBRM: WideBand Receiver Module)은 사용환경에 따라 수광하는 광파워 가 급격히 변화하여도 동작할 수 있도록 dynamic range(DR) 가 $27 \mathrm{~dB}$ 이상으로 넓게 설계하였다. ${ }^{[8]}$ 이를 위해 TIA 단에 서 High-gain mode와 이로부터 $10 \mathrm{~dB}$ 감쇄 특성을 가진 Lowgain mode의 두 상태에서 각각 동작할 수 있도록 설계하였 으며, 각 모드의 $\mathrm{DR}$ 이 $17 \mathrm{~dB}$ 이상이므로 전체의 $\mathrm{DR}$ 이 27 $\mathrm{dB}$ 이상을 만족하며, high-gain mode와 low-gain mode의 상 태변화 시 이 변환이 빠른 시간 내에 실행되도록 설계하였 다. 본 연구에서는 이득 변환이 one-step 방식으로 이루어지 며, 참고문헌 [8]에 나타낸 이득 제어 방식은 기본 이득제어 가 $3 \mathrm{~dB}$ 간격의 다섯 스텝으로 이루어져 있어서 전체의 dynamic range는 $32 \mathrm{~dB}$ 로서 본 연구의 one-step 방식보다 조금 더 넓 은 특성을 보이나 이득 제어 부분을 제외하고는 본 연구결과 와 동일한 구조 및 특성을 갖는다. (그림 12)에 제작된 모듈 의 입력 광펄스에 대한 출력펄스를 나타내었고, (그림 13)에 이득변환 시간을 나타내었다. 이득변환시간은 High-gain mode에서 Low-gain mode로 변환은 500ns 이내에 안정화 되 며, Low-gain mode에서 High-gain mode로의 변환은 순간적 으로 이루어짐을 볼 수 있다. 이 변환은 $1 \mathrm{us}$ 이내로 충분히 안정적으로 사용할 수 있는 값을 보였다. (그림 12)에 나타낸 dynamic range는 High-gain mode와 Low-gain mode의 기울 기가 다르게 나타났으며, 각 모드에서 매우 선형적임을 알 수 있고 따라서 기울기의 차이는 소프트웨어를 통해 충분히 보정할 수 있다. Total dynamic range는 $27 \mathrm{~dB}$ 이고, 한 모드에 서 dynamic range는 $17 \mathrm{~dB}$ 이상임을 확인하였다.

\section{V. 결 론}

본 연구에서는 LIDAR 시스템에 응용할 수 있는 초고속 대면적 $\mathrm{APD}$ 를 이용한 광검출기 모듈을 제작하고, 그 특성을 측정하였다. $200 \mathrm{um} \mathrm{InGaAs-APD}$ 칩은 $\mathrm{AlN}$ 기판 상에 flip-chip bonding 방법으로 제작하였으며, chip-on-submount 
상태 및 동작전압에서 $1.7 \mathrm{pF}$ 이하의 정전용량과, $10 \mathrm{nA}$ 의 암전류 특성을 보였다. 자체 설계-제작한 TIA는 $7.5 \mathrm{kOhm}$ 의 feedback impedance를 보였으며, 이를 이용한 모듈의 제작 결과 $0.850 \mathrm{mV}$ 이하의 잡음전압을 보였다. 또, $1 \mathrm{~ns}$ 의 펄스 폭에 대해 $27 \mathrm{~dB}$ 의 dynamic range, $150 \mathrm{nW}$ 의 MDS 신호에 대해 15 이상의 신호대 잡음비를 나타내었으며, 이는 높은 이득특성과 저 잡음 특성에 기인하는 것이다. TIA의 highgain mode와 low-gain mode 사이의 변환은 $500 \mathrm{~ns}$ 이내에 이루어졌다. 이러한 특성들은 저자들이 아는 한 최고의 성능 을 나타낸 것으로 설계 및 제작이 잘 이루어진 것이며 향후 LIDAR/LADAR 시스템 기술의 발전에 크게 이바지할 것으 로 생각된다.

\section{References}

1. http://en.wikipedia.org/wiki/LIDAR.

2. http://en.wikipedia.org/wiki/Time-of-flight_camera\#cite_no te- 16 .

3. http://www.advancedscientificconcepts.com/products/overv iew.html.

4. M. Juberts and A. Barbera, "Status report on next generation LADAR for driving unmanned ground vehicles," Proc. SPIE 5609, 1-12 (2004).

5. R. Sudharsanan, P. Yuan, J. Boisvert, P. McDonald, T. Isshiki, S. Mesropian, E. Labios, and M. Salisbury, "Single photon counting geiger mode $\mathrm{InGaAs}(\mathrm{P}) / \mathrm{InP}$ avalanche photodiode arrays for 3D imaging," Laser Radar Technology and Applications XIII, M. D. Turner and G. W. Kamerman, ed., Proc. SPIE 6950, 69500N (2008).

6. R. M. Marino, T. S. Stephenes, R. E. Hatch, J. L. McLaughlin, J. G. Mooney, M. E. O’Brien, G. S. Rowe, J. S. Adams, L. Skelly, R. C. Knowlton, S. E. Forman, and W. R. Davis, "A compact 3D imaging laser radar system using Geiger-mode APD arrays: system and measurements," Laser Radar Technology and Applications VIII, G. W. Kamerman, ed., Proc. SPIE 5086, 1-15 (2003).

7. http://velodynelidar.com/lidar/lidar.aspx.

8. T. H. Ngo, C. H. Kim, Y. J. Kwon, J. S. Ko, D. B. Kim, and H. H. Park, "Wideband receiver for a three-dimensional ranging LADAR system," to be published in IEEE Transactions on Circuit and System II (2012).

9. C. Y. Park, K. S. Hyun, J. S. Kim, S. G. Kang, M. K. Song, E. S. Nam, and H. M. Kim, "Analysis of avalanche gain with multiplication layer width and application to floating guard ring avalanche photodiode," Inst. Phys. Conf., Ser. No145: Compound Semiconductors 1995, J. C. Woo and Y. S. Park, ed. (IOP Publishing Ltd., Bristol and Philadelphia, 1995), pp. 1125-1128.

10. C. Y. Park, K. S. Hyun, S. G. Kang, and H. M. Kim, "Effect of multiplication layer width on breakdown voltage in InP/InGaAs avalanche photodiode," Appl. Phys. Lett. 67, 3789-3791 (1995).

11. K. S. Hyun and C. Y. Park, "Breakdown characteristics in InP/InGaAs avalanche photodiode with p-i-n multiplication layer structure," J. Appl. Phys. 81, 974-984 (1997).

12. S. R. Forrest, "Avalanche photodetector receiver sensitivity," Chapt. 4 in Semiconductors and Semimetals, 22 part D, W. T. Tsang, ed. (Academic press, Homdel NJ, USA, 1985). 